\title{
Reaction of Aldehydes and Ketones with Boron Triisopropoxide. The Meerwein-Ponndorf-Verley Type Reduction of Boron Alkoxides. 1
}

\author{
Jin Soon Cha ${ }^{*}$ and Jae Hyung Park \\ Department of ( 'hemistry: Institute of Natural Sience and Instimte of tew Materal (hemisty, \\ Teungnam Liversin, Gyongsan 712-749, Korea \\ Received IArch 12,2002
}

Key words : Boron trisopropoxide, MPV reduction. Reduction of carbonyl compounds with $B(\mathrm{OR})_{3}$

Meenwein-Ponndorf-Verley (MPV) reductions of aldehydes and ketones las been known for a long time. ${ }^{1}$ Although its importance has declined due to the introduction of complex metal hydrides. there appear to be several instances where its application is preferable. Extensive studies of the experimental conditions of the reaction have been performed. dealing with the nature of reducing agents ${ }^{\mathrm{lit}}$ or of catalysts. The most widely used reducing agents are aluminum aldoxides ${ }^{1 n}$ but .t/-chloro, $4 /$-alkoxy-. .t/-dialkylamino- and $. A /$-py rrolyldiisobutylalanes have also been reported as new MPV type reducing agents with a high selectivity: ${ }^{2-5} \ln$ addition to that. some other metal alkoxides? such as zirconium alkoxides. "plutonium alkoxide and some lanthanide alkoxides $^{8}$ have been reported as catalysts in a MPV type reduction of carbonyl compounds.

Nearly twenty years ago. Brown and coworkers developed a new asymmetric reducing agent. diisopinocampheylchloroborane $\left(\mathrm{lpc}_{2} \mathrm{BCl}\right){ }^{9}$ The reaction of prochiral ketones with $\mathrm{lpc}_{2} \mathrm{BH}$ proceeds through a dely droboration of isopinocampheyl group after the coordination of boron atom to carbonyl oxygen: this seems to be another type of MPV reduction. Since then. we have developed other derivatives such as diisopinocamphey lly droxy- and disopinocampheylalkoxyboranes and found that these reagents are highly selective MPV type reducing agents in the reduction of carbonyl compounds. ${ }^{[1,1]}$

These interesting results led us to examine the reducing characteristics of boron alkoxides, which might serve as a comparative partner of aluminum alkoxides. To our knowledge. the MPV type reduction of boron alkoxides has not appeared yet in a literature. We wish now to report a sy stematic study on the reducing action of boron triisopropoxide toward a series of representative aldehy des and ketones.

The reaction of aromatic aldehydes examined with the reagent in THF at $25^{\circ}$ or in refluxing THF under a slow stream of nitrogen showed actually no reactivity. as shown in Table 1 . In contrast to that. aliphatic aldehydes were quite reactive to reduction both at $25^{\circ}$ and in refluxing THF. and could be employed for this purpose. However. side reactions are significant ${ }^{i=}$ and hence yields become lower as the reaction goes on. Therefore. short period of reaction time is required to minimize the undesirable side reaction. Similar side reactions were also found in the MPV reaction of aldehydes with aluminum triisopropoxide.'
Table 1. Reaction of Aldehy des with Boron Triisopropoxide" in letrahydrofuran under Steam of Nitrogen

\begin{tabular}{|c|c|c|c|}
\hline \multirow{2}{*}{ Compound } & \multirow{2}{*}{ Time (h) } & \multicolumn{2}{|c|}{ Yield of alcohol $(" w)^{\prime \prime}$} \\
\hline & & $25^{\prime \prime}$ & reflux \\
\hline benzaldehyde & 72 & trace & trace \\
\hline$p$-nitrobenzaldehyde & 72 & trace & trace \\
\hline$p$-tolualdehỵde & 72 & trace & trace \\
\hline p-chlorobenzaldehyde & 72 & trace & trace \\
\hline \multirow[t]{4}{*}{ caproaldehyde } & 1 & 18 & 72 \\
\hline & 3 & 47 & 66 \\
\hline & 24 & 50 & 54 \\
\hline & 72 & 45 & $1^{\circ}$ \\
\hline \multirow[t]{3}{*}{ isobuțraldehyde } & 3 & 94 & 92 \\
\hline & 6 & 79 & 70 \\
\hline & 24 & 80 & \\
\hline \multirow[t]{2}{*}{ trimethỵlacetaldehỵde } & 3 & 95 & 94 \\
\hline & 6 & 92 & 80 \\
\hline \multirow[t]{2}{*}{ cyclohexancearboxaldehy de } & 3 & 92 & 90 \\
\hline & 6 & 83 & 83 \\
\hline
\end{tabular}

"Ratio ol reagent to compound is $1: 1$. "Analy zed by GC with a suitable intemal standard. 'Along with some unidentilied condensation products.

On the other hand. the reduction of simple ketones can be carried out very easily, except for aryl alkyl and diaryl ketones. In simular to the case of aldehydes, aromatic ketones were resistant to reduction both at $25^{\circ}$ and in refluxing THF, and could not be employed for this purpose. In general. the yields in the reaction of simple ketones range from 75 to $100 \%$. The time required for a reduction varies greatly with the structure of ketones. Practically. the reflux conditions are preferable. Some sterically hindered ketones, such as norcamphor and camphor. are resistant to reduction even in refluxing THF for $72 \mathrm{~h}$.

In the reaction of both aldehydes and ketones. the acetone formed should be removed from the equilibrium mixture by a slow stream of nitrogen: otherwise, the yields are often quite lower.

As shown in Table 2. the remarkable difference in rates in the reduction by boron triisopropoxide between aliphatic ketones and aromatic ketones suggests the possibility of achieving the selective reduction of a carbonyl group attached th aliphatic moieties in the presence of a carbonyl group attached to aromatic moieties. This possibility was tested in 
Table 2. Reaction of Ketones with Boron Triisopropoxide" in Tetrahydrofuran under Stream of $\mathrm{Nitrogen}$

\begin{tabular}{|c|c|c|c|}
\hline \multirow{2}{*}{ Compound } & \multirow{2}{*}{ Time $(\mathbf{h})$} & \multicolumn{2}{|c|}{ Vield of alcohol (\%) } \\
\hline & & $25^{\prime \prime}$ & reflux \\
\hline acctophenone & 72 & trace & trace \\
\hline buty rophenone & 72 & tracs & trace \\
\hline beszophessone & 72 & 0 & 0 \\
\hline 2-butanotsc & 24 & 75 & 99 \\
\hline \multirow[t]{4}{*}{ 2-heptanotc } & 3 & 13 & 18 \\
\hline & 6 & 18 & 25 \\
\hline & 24 & 56 & 97 \\
\hline & 72 & 97 & 98 \\
\hline cyclohexanone & 6 & 90 & 99 \\
\hline 2-methylcyclohexanone & 6 & 86 & $100^{\circ}$ \\
\hline 3-methy lcyclohexanone & 6 & 82 & $98^{d}$ \\
\hline 4-methylcyclohexanone & 6 & 81 & $99^{\circ}$ \\
\hline 4-f-butyllcyclohexanone & 24 & 80 & $100^{t}$ \\
\hline 3.3.5-trimethyleyelohexanone & 24 & 75 & $101 \%$ \\
\hline norcamphor & 72 & & 0 \\
\hline camphor & 72 & & 0 \\
\hline
\end{tabular}

"Ratio of compound to reagent is $1: 1$. "Analyzed by $\mathrm{C}_{\mathrm{C}} \mathrm{C}$ with a suitable intertal standard. $68 \%$ of troms-isomer. $" 76 \%$ of $\mathrm{cos}$-isomer. $80 \%$ of waws-isomer. ${ }^{7} 75 \%$ trons-isomer $" 60 \%$ of cis-isomer.

the following manner. A mixture of equimolat amounts of 2heptanone and actophenone was treated with I mol epuiv of boron triisopropoxide. Alter 24-h reaction in relluxing TIJF, GC analysis of the product revealed a $96 \%$ yicld of $2-$ heptanol, with only traces of 1 -phenylethanol.

In general, the reaction with boron trisopropoxide is much

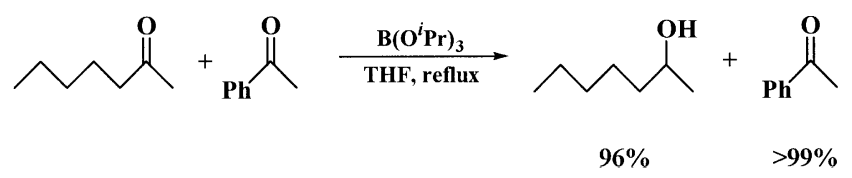

milder than that with aluminum triisopropoxide. Boron triisopropoxide only can reduce aliphatic aldehydes and kelones among the carbonyl compounds, whereas the aluminum reagent reduces most carbonyl compounds irrespective of its structure. ${ }^{\text {ld }}$ In addition to that, a preliminary experiment revealed that boron triisoprpoxide does not alfect other groups such as carboxylic acids, esters, nitriles, amides and acid chlorides, except for cpoxides. Therefore, we will explore in more detail the possibility achieving a selective reduction of particular organic functional groups.

The following procedure was illustrative for reduction of carbonyl compounds with boron triisopropoxide. The apparalus consists of a $50 \mathrm{~mL}$ flask with a side-arm, cquipped with a $50 \mathrm{~cm}$ Vigreux column, the upper end of which is connected 10 a downward-directed, water-cooled condenser leading to a mercury bubblet. ${ }^{13.14}$ Into the flask $5 \mathrm{~mL}$ of a 1.0 $\mathrm{M}$ solution of $\mathrm{BH}_{3}$ in $\mathrm{TH} I F(5 \mathrm{mmol})$ was placed and the flask was immersed into an ice-water bath. To this $1.0 \mathrm{~g} \mathrm{of}$ isopropyl alcohol ( $16.5 \mathrm{mmol}$ ) was added dropwise. $\Lambda$ lier the hydrogen evolution ceased, the mixture was stirted for an additional $30 \mathrm{~min}$ at room temperature. ${ }^{15}$ Into this solution of boron triisopropoxide in THF $0.57 \mathrm{~g}$ of $2-$ heptanone $(5 \mathrm{mmol})$ was injected, and allow to flow a slow stream of dry nitrogen just over the surface of reaction mixture using a 6 -inch needle with stirring at $25^{\circ}$. After $72 \mathrm{~h}$ at that temperature, tridecane (5 mmol) was added as an internal standard and mixture was quenched by addition of water. The aqueous layer was saturated with $\mathrm{K}_{2} \mathrm{CO}_{3}$ and the organic layer was dried over anhydrous $\mathrm{MgSO}_{4}$. GC analysis of the organic layer indicated the presence of 2 -heptanol in a yield of $97 \%$. The other results in appropriate time interval were listed in Table 2.

Acknowledgment. This work was supporled by a Korea Rescarch Foundation Grant (KRF-2000-0/5-DP0269). The "B NMR spectra were recorded on a Bruker $\Lambda \mathrm{RX} 300$ spectrometer at the Yeungnam University Instrumental Analysis Center.

\section{References and Notes}

1. (a) Mecrueits. H.: Schmidt. R, int, 1925. iff. 221, (b) Ponndorf. W. Atgew: Chen, 1926, 39. 138, (c) Verley. M. Bull. Soc. Chin. Rr. 1925. 37.537. (d) Wilds. A. S. Org. React, 1944. 2. 178.

2. (a) Cha. J. S.: Kwon. O. O.: Kwon. S. Y.: Kim. I. M.: Seo. W. W.: Chang. S. W. Symtett 1095. 1055. (b) Cha. J. S.: Kwon. O. O.: Kwon. S. Y. Buth. Koretn (hem. Soc. 1905. 16. 1009.

3. (a) Cha. J. S.: Kwon. O. O.: Kwon, S. Y.: Kim, J, M.: Seo. W. W.: Chang. S. W. Bull. Korem Chem, Soc. 1996. 17. 221, (b) Cha. J, S: Kivon. O. O.: Kivon, S. Y. Org. Prep. Proced. In. 199, 28. 355. (c) Cha. J. S.: Kwon. O. (O. . Org. (Wem. 1997. 62. 3019 . (d) Cha. J. S.: Kwon. O. O. Bull. Koretn (hem. Sot. 1907. I8. 689. (e) Cha. I. S.: Kwon. O. O.: Kim. I. M.: Chun. I. I I.: Lee. Y. S.: I.cc. H. S.: Cho. S. D. Whid. 1998. 19.236.

4. Cha, J. S.: Kwon, S. Y.: Kwon, O. O.: Kim. I, M. Buh. Korean Chent. Sot. 1996, /7.900

5. Kwon. O. O.: Cha. I. S. Bull. Koreth (hem. Soc. 2000. 21. 659.

6. Seebach. D.: Weidmann. B.: Wildler. L. In Motern Sinthetic Methods: Scheliold. R.. Ed.: Bem: New York. 1983: vol. 3. p 217.

7. Wamer. B. I': L’Alessio. J. A.: Morgan III. A. N.: Burns. C. J.: Schaks. A. R.: Watkin. J. G. Inong. Chim. Acto 2000. 309. 45.

8. (a) Namy. 1. L.: Souppe. 1.: Collin. J.: Kagan. H. B. J. Org. Chem. 1984. 49. 2045. (b) l.ebrun. A.: Namy. J.-l.: Kagan. 1 I. B. Tetrahedron Lett. 1991. 32. 2355. (c) Fivans. D. A.: Nislson. S. Cu.: Ciagne. M. R.: Muci. A. R. J. Am. (hem. Soc. 1993. 1/5.9800).

9. Chandrasekbaran. I.: Ramachandrats. I'. V.: Brown. H. C.,. O.g. Chenr. 1985. 50. 5446.

10. Cha. J. S.: Kim. E. J.: Kiwon. O. O.: Kwon. S. Y.: Seo. W. W.: Chang. S. W. Ong. Prep. Proced Int 1995. 27. 541.

11. Cha. J. S.: Kim. Г.. J.: Kwon. (). O.: Kim. J. M. Bulf. Korem Chem. Soc. 1995. 16.691.

12. Aldol condetsations oltet are possible not only between iwo molecules of the aldehyde but also between the aldely de and acetome formed. ${ }^{\text {ld }}$

13. All glassware used was dried thoroughly in an oven. assembled hot. and cooled under a stream of dry nitrogen prior to use. All reation and manipulations of air- and moisture-sensitive materials were carricd out using standard techniques for handling airsensitive materials. 't Tetralyzdrofuran (THF) was dried over sodium-benzophenone ketyl and distilled. All liquid materials were transferred by using hypodermic syringes.

14. Browtn. I1. C.: Kramer. (j. W.: Levy. A. B.: Midland. M. M. Oyganic Siwhesis via Boremes: Wiley-Interscience: New York. N. Y.. 1975.

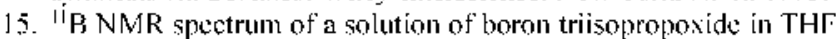
showed a sharp singlet centered at $\delta 18$ ppm relative to BГ $\cdot$ OГ.t. 